\title{
The strategic integration of operational assessment into the regeneration of urban wastelands in sustainable neighborhoods
}

\author{
M. Laprise, S. Lufkin \& E. Rey \\ Laboratory of Architecture and Sustainable Technologies (LAST), \\ Ecole Polytechnique Fédérale de Lausanne (EPFL), Switzerland
}

\begin{abstract}
In the context of the post-industrial European city, urban wastelands offer an important potential for buildable surfaces as well as an opportunity to revitalize and densify some portions of the existing built fabric. Initiatives of this type are now strongly fostered by land use policies. However, we note that in most projects, references to the concept of sustainable development are partial and superficial. Yet, an optimized transformation of urban wastelands into sustainable neighborhoods cannot rely simply on density issues or environmental considerations. It requires a proactive search for global quality, closely linked to the project dynamic, and a continuous assessment of the many dimensions of sustainability specifically adapted to these sites. This paper shows how a strategic integration of operational assessment into the regeneration of urban wastelands addresses these targets specifically. Preliminary research has allowed the identification of a set of criteria and indicators based on specific characteristics of urban wasteland transformations, as well as the achievement of a first test application on a concrete project in Neuchâtel (Switzerland). On the basis of these works, a strategy is then developed to transpose the set into a structured digital monitoring tool in order to create an operational assessment applicable to a multitude of similar projects. Ultimately, it aims to concretely facilitate the transformation of urban wastelands into sustainable neighborhoods by providing useful bases to stakeholders involved in their management.

Keywords: urban strategy, architectural design, urban wasteland, sustainable neighborhood, sustainability assessment, indicator system, monitoring tool, project monitoring.
\end{abstract}




\section{Introduction}

As part of the polycentric and compact city model [1,2], the regeneration of urban wastelands contributes to the revitalization and densification of cities. Yet, it has to be recognized that these conditions are necessary but insufficient to reach more sustainable cities $[3,4]$. Indeed, sustainability is not inherent to the transformation of urban wastelands [5]; frequently, attention is drawn only to environmental considerations since they are the most simple aspects to define [6].

Given both qualitative and quantitative potentials of urban wastelands, few studies have developed methods to assess simultaneously the environmental, sociocultural and economic dimensions of sustainability from varying perspectives [6-10]. However, our observations show that these methods are limited to procedural frameworks, checklist of sustainability objectives or single assessment. In any case, we notice a dissociation from the project dynamics throughout the process of wasteland transformation. As a result, none of these approaches are currently being used in practice.

Trying to fill this gap, a preliminary research project has resulted in an operational indicator system for the integration of sustainability into the design process of urban wasteland regeneration (SIPRIUS). It has been tested on a wasteland transformation project in order to validate its relevance and applicability [11]. Using this experience as a first theoretical basis, a research project is currently conducted at EPFL [12] in order to transpose this indicator system into a digital monitoring tool for integrating operational assessment into the project dynamics. The present paper aims at describing the main features of the SIPRIUS system, as well as the future phases of this ongoing research. It will also present the first achievements: the identification of an appropriate monitoring tool which will serve as a base and the required adaptations.

\section{From urban wastelands to sustainable neighborhoods}

The transformation of urban wastelands into sustainable neighborhood is not a spontaneous process. To concretize the objectives of sustainable development, an operational assessment appears necessary. As stated by Hollander et al. [13], having a clear idea of where the project is heading in terms of sustainability gives strong basis for its future development. To respond adequately to its role, the assessment must take into account the specific characteristics of this type of projects [14]. As a matter of fact, wastelands are not ordinary sites: large scale areas cut off from their surroundings, hosting various types of buildings, they are characterized by a strong identity (real or perceived contamination, social and economic stigma, cultural symbol, sense of insecurity, etc.). Urban wasteland transformation projects are also singular in reason of the complexity of their process: long duration, variation of conditions, multiple stakeholders, etc. Given their specificity, a tailor made assessment is the only way to provide decision makers with a realistic account of the situations [15]. 


\subsection{Integrated operational assessment}

These considerations call for an integrated operational assessment of sustainability issues, which meets the general requirements expressed in Table 1.

Table 1: Requirements for an integrated operational assessment.

\begin{tabular}{|l|l|}
\hline General requirement & Description \\
\hline Search for global quality & $\begin{array}{l}\text { Wide coverage of sustainability principles; } \\
\text { assessment parameters take into account } \\
\text { environmental, economic and social aspects in a } \\
\text { holistic way. }\end{array}$ \\
\hline $\begin{array}{l}\text { Specificity of urban } \\
\text { wasteland transformation } \\
\text { projects }\end{array}$ & $\begin{array}{l}\text { Parameters are adapted to the specificities of the } \\
\text { site and of the project process, addressing the } \\
\text { issues of sustainability assessment. }\end{array}$ \\
\hline Monitoring principles & $\begin{array}{l}\text { Assessment is performed easily and in an iterative } \\
\text { way at different stages of the project. Allow a } \\
\text { visualization of the results in terms of } \\
\text { sustainability in order to follow and act on } \\
\text { performance trends. }\end{array}$ \\
\hline
\end{tabular}

\section{Theoretical indicator system for operational assessment}

Preliminary work has led to the creation of a comprehensive indicator system entitled SIPRIUS [11]. The methodology behind its construction is based on three successive steps.

First, the selection of criteria is divided in two categories to represent the large scale and multidimensional aspects of wastelands: criteria that refer to the context, which implications go beyond the site's limits, and criteria that refer to the project, which influence stays within the site's boundaries. Criteria are distributed evenly among environmental, social and economic aspects.

Second, indicators are selected to assess each criterion following fundamental rules $[16,17]$. In that regard, indicators need to be exhaustive, relevant, sensitive, objective, accessible and readable.

Third, in order "to measure" and give "value" to each indicator, reference values are allocated. Four reference values are available: Limit Value $\left(\mathrm{V}_{\mathrm{L}}\right)$ or "veto value", Average Value $\left(\mathrm{V}_{\mathrm{A}}\right)$, Target Value $\left(\mathrm{V}_{\mathrm{T}}\right)$ and Best Practice Value $\left(\mathrm{V}_{\mathrm{B}}\right)$. These values are achieved incrementally, that is to say by "levels of performance". Results, both qualitative and quantitative, can be measured and compared without using any numerical aggregation.

Altogether, SIPRIUS is composed of 9 criteria and 21 indicators relating to the context and 12 criteria and 21 indicators relating to the project (Rey [11]). 


\subsection{Test application}

Concurrently with the construction of the indicator system, a test application was carried out on the transformation of an urban wasteland into a sustainable neighborhood, namely the Ecoparc neighborhood in Neuchâtel, Switzerland. This step has allowed to make iterative improvements and practical settings as well as to validate the adequacy and the relevance of SIPRIUS [11].

For the sake of concision, results of three indicators assessing context criteria and three indicators assessing project criteria - representative of environmental, social and economic dimensions - are presented as examples in two synoptic tables (Figure 1 and Figure 2).

\begin{tabular}{l}
\hline CONTEXT \\
\hline $\mathbf{C 3}$ Noise
\end{tabular}

Figure 1: Results of the test application. Selection of three context criteria.

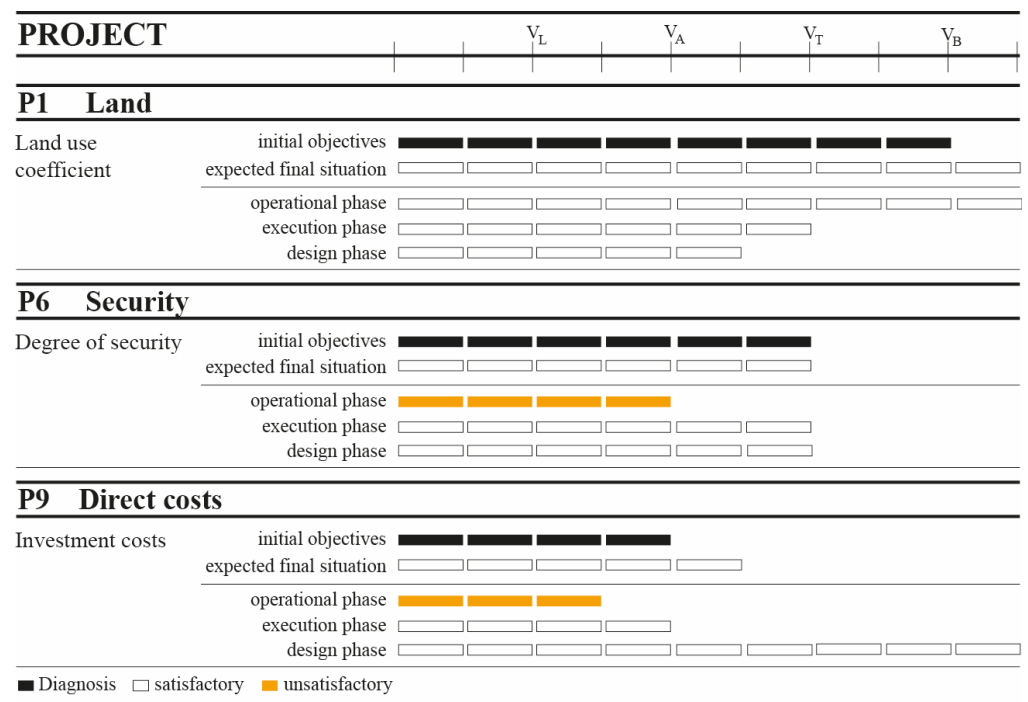

Figure 2: Results of the test application. Selection of three project criteria. 


\subsection{Toward a digital monitoring tool}

The test application has revealed that SIPRIUS answers most requirements for an operational assessment. As a point of fact, the indicator system covers equally and simultaneously the three dimensions of sustainable development with the specificities of urban wasteland at its core. It also sets a sound basis for monitoring principles by working with reference values. Moreover, the synoptic table clearly highlights strengths and weaknesses of the project with a visualization of its performance at different stages.

Besides, the test application has shown that SIPRIUS contributes to raise awareness of the integration of sustainability principles into urban wasteland transformation projects. In spite of that, successful operational assessment depends principally on the degree of participation and motivation of key stakeholders. To this end, integration of operational assessment into the transformation of urban wasteland - that is to say the transposition of the indicator system in a digital monitoring tool - would concretely support the inclusion of sustainability objectives.

\section{Strategic integration of operational assessment}

Operational assessment must be integrated in the project dynamics in a reflexive approach that allows monitoring, or in other words continuous and iterative setting of the project's objectives. It becomes both a decision-making tool by showing the right balance between complex information and transparency of results and a communication tool for the many different involved stakeholders (private property developers, local authority, public developers, professional advisors, etc.).

\subsection{Digital monitoring tool requirements}

Integrated operational assessment seeks to cover several phases, simultaneously giving overviews and precise pictures of the project's performance. A digital monitoring tool brings together steps that occur before, after and in between as shown in Table 2.

Table 2: Correlation between assessment and phases of a project.

\begin{tabular}{|l|l|}
\hline Assessment phase & Description \\
\hline Ex ante assessment & $\begin{array}{l}\text { Diagnosis of the initial situation. Estimation and comparison } \\
\text { of expected performance. Forward-looking evaluation. }\end{array}$ \\
\hline $\begin{array}{l}\text { In itinere } \\
\text { assessment }\end{array}$ & $\begin{array}{l}\text { Regular verification and project optimization. Assistance to } \\
\text { problem solving and fine-tuning. Connects various stages of } \\
\text { the project. Supports evaluation. }\end{array}$ \\
\hline Ex post assessment & $\begin{array}{l}\text { Synthesis of general and specific characteristics of the } \\
\text { project. Balance sheet between performance expectations } \\
\text { and obtained values. Acquisition of new knowledge for the } \\
\text { benefit of future projects. Recapitulative evaluation. }\end{array}$ \\
\hline
\end{tabular}


Essential to the integration of an operational assessment, the digital monitoring tool must be used easily on a regularly basis. Required qualities are shown in Table 3 .

Table 3: Qualities for the digital tool.

\begin{tabular}{|l|l|}
\hline Quality & Description \\
\hline Database & $\begin{array}{l}\text { Availability of structured information on sustainability issues } \\
\text { to allow consistency and transparency of the evaluation } \\
\text { system. }\end{array}$ \\
\hline Type of indicators & $\begin{array}{l}\text { Integration of quantitative and qualitative indicators, } \\
\text { evolving with the requirements and features of the project. }\end{array}$ \\
\hline Iteration & $\begin{array}{l}\text { Constant evolving dynamics, the monitoring tool allows both } \\
\text { to monitor the project and influence according to the results. }\end{array}$ \\
\hline Simplicity & $\begin{array}{l}\text { Easy to use, to operate and understand as well as to report } \\
\text { and communicate results. }\end{array}$ \\
\hline Communication & $\begin{array}{l}\text { Controlled by a project leader but communicable to a } \\
\text { majority of stakeholders from various backgrounds. }\end{array}$ \\
\hline Integration & $\begin{array}{l}\text { Applicable to a variety of urban wasteland transformation } \\
\text { projects and extended to general practice. }\end{array}$ \\
\hline
\end{tabular}

\subsection{From indicator system to digital monitoring tool}

\subsubsection{Selection of digital monitoring tool}

The concept of monitoring is used in different types of activities where management of sustainability is taken into account in operational terms. If the indicators are different, modalities inherent to sustainability monitoring of a private company, of a public service or of a project development share a large number of similarities.

Given these similarities, it appears appropriate to build on an existing tool. An analysis allowed us to identify a software program which offers structured and continuous assessment through the project process and holds the qualities required for a digital monitoring tool (Table 2 and 3). Entitled OKpilot, it is developed as a user-friendly sustainability monitoring tool for business and public communities. OKpilot is a SaaS (Software as a Service) platform which ensures smooth implementation, simple maintenance and lower costs GLOBALITE Management [18].

\subsubsection{Adaptation of digital monitoring tool}

Preliminary work has confirmed the relevance and the technical feasibility of a transposition of OKpilot to the field of the built environment. Compatibility between the two devices and integration of the SIPRIUS indicator system within the digital monitoring tool OKpilot is feasible through a defined number of adaptations of the latter:

1. Database: All information and resources necessary for the assessment of each indicator such as norms, laws or measurement methods must be gathered and easily available within OKpilot. 
2. Relevance: SIPRIUS is composed of 42 indicators. The monitoring tool must be organized in a way that users can choose among the most relevant ones to assess. It is worth noting that a list of key indicators, mandatory to the assessment, is provided.

3. Tree diagram: The monitoring tool must be sufficiently adapted to the structure of the indicator system (criteria - context and project - for each dimension of sustainability and indicators). In this sense, it will be necessary to add a level in the tree diagram structure of OKpilot for clear identification of the three dimensions of sustainability.

4. Reference value: OKpilot works with relative values (expressed as a percentage). A main adaptation consists of computer programming in order to be able to compare results based on the reference value system (express as level of performance: Limit, Average, Target and Best Practice Value).

5. Graphical representation: OKpilot shows the results of the assessment through a regular histogram, with continuous bar as in Figure 3. An adaptation is necessary to incorporate a synoptic table, with incremental values to represent levels of performance and allow clear communication of sustainability objectives.

6. Reports: Since there is no final aggregation, reports offering various options to display the results must be developed: showing a selection, the whole or key indicators, assessment at a specific point in time or an overview of the project objectives.

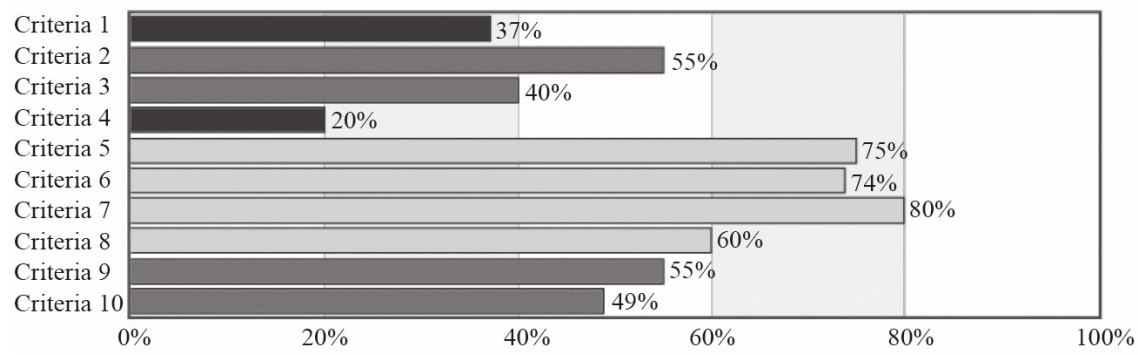

Figure 3: Example of OKpilot's bar chart showing results expressed in percentage and aggregated by criteria (GLOBALITE management, 2014).

\section{Discussion}

Through this adaptation work, a new monitoring tool of sustainability will be developed with its own specificity in terms of content and its own identity in terms of presentation. This strategic integration of operational assessment into the process of urban wasteland regeneration fully complies with the requirements of global quality, adequacy with the specificities of the project and monitoring principles. This tool is meant to be collaborative among the key involved stakeholders, to give useful and relevant bases and outputs in addition to be 
applicable to a multitude of projects of this type. Therefore, it is expected to contribute to an increased sustainability of neighborhoods.

However, research must go further and feature case studies. This step is necessary in order to validate the technical and practical modalities of the assessment performed by this monitoring tool. Hence, case studies of urban wasteland transformations into sustainable neighborhoods, at different stages of their process, of different sizes and in different contexts in Europe have to be performed. These studies will be included in the next stages of the ongoing research carried out at EPFL and will lead to various publications in the coming months.

\section{Conclusion}

Integrated operational assessment requires a search for global quality, must be adapted to the specificities of urban wasteland transformation projects and requires the integration of monitoring principles. The SIPRIUS indicator system, tested through a conclusive test application, covers environmental, social and economic aspects of this type of projects. In addition, its assessment method (reference values and synoptic table) sets the basis for a continuous and structured follow-up of urban wasteland transformations. The transposition of this indicator system into a digital monitoring tool is a strategic integration of this operational assessment into the project dynamics. It is expected to contribute significantly to the integration of sustainability objectives into new resulting neighborhoods. Further work suggests an application of the monitoring tool to several case studies in order to make iterative improvements and validations. Research is now starting with the adaptation of the digital monitoring tool.

\section{References}

[1] Williams, K., Burton, E. \& Jenks, M., Achieving Sustainable Urban Form, London: Taylor \& Francis, 2000.

[2] Rogers, R. \& Gumuchdjian, P., Cities for a small planet, Icon Editions. Boulder, Colo.: Westview; 1998.

[3] Andres, L. \& Bochet, B., Regenerating brownfields and promoting sustainable development in France and in Switzerland: what convergences? Revue d'Economie Régionale \& Urbaine, 4, pp. 729-46, 2010.

[4] Rey, E., Lufkin, S., Renaud, P. \& Perret, L., The influence of centrality on the global energy consumption in Swiss neighborhoods. Energy Buildings, 60, pp. 75-82, 2013.

[5] Eisen, J.B., Brownfield policies for sustainable cities. Duke Environmental Law \& Policy Forum, 9, pp. 187-229, 1999.

[6] Williams, K. \& Dair, C., A framework for assessing the sustainability of brownfield developments. Journal of Environmental Planning and Management 50 (1), pp. 23-40, 2007.

[7] Pediaditi, K., Wehrmeyer, W. \& Chenoweth, J., Monitoring the Sustainability of Brownfield Redevelopment Projects: The Redevelopment 
Assessment Framework (RAF). Contaminated Land \& Reclamation, 13(2), pp. 173-83, 2005.

[8] Wedding, G.C. \& Crawford-Brown, D., Measuring site-level success in brownfield redevelopments: A focus on sustainability and green building. Journal of Environmental Management, 85(2), pp. 2483-95, 2007.

[9] Franz, M., Pahlen, G., Nathanail, P., Okuniek, N. \& Koj, A., Sustainable development and brownfield regeneration. What defines the quality of derelict land recycling? Environ Sciences, 3(2), pp. 135-51, 2006.

[10] CABERNET. Sustainable Brownfield Regeneration: CABERNET Network Report, University of Nottingham: Nottingham; 2006.

[11] Rey, E., Régénération des friches urbaines et développement durable : vers une évaluation intégrée à la dynamique du projet. Louvain-La-Neuve: Presses Universitaires; 2012.

[12] Laprise, M. Intégration des enjeux de la durabilité aux projets de régénération de friches urbaines: Du référentiel théorique à l'outil de monitoring opérationnel. Thesis in progress within the Laboratory of Sustainable Architecture Technologies (LAST), EPFL, 2014. http://last.epfl.ch/sipriusresearch

[13] Hollander, J.B., Kirkwood, N. \& Gold JL., Principles of brownfield regeneration: cleanup, design, and reuse of derelict land. Washington: Island Press; p. 8, 2010.

[14] Edwards, D., Pahlen, G., Bertram, C. \& Nathanail P., Best Practice Guidance for Sustainable Brownfield Regeneration. RESCUE Regeneration of European Sites in Cities and Urban Environments: Nottingham; 2005.

[15] Sharifi, A. \& Murayama, A., A critical review of seven selected neighborhood sustainability assessment tools. Environmental Impact Assessment Revue, 38, pp. 73-87, 2013.

[16] Bossel, H., Indicators for Sustainable Development: Theory, Method, Applications. Winnipeg, Canada: IISD International Institute for Sustainable Development; 1999.

[17] Bell, S. \& Morse, S., Measuring sustainability: learning by doing. Reprint 2006. London: Earthscan Publications; 2006.

[18] GLOBALITE Management. OKpilot - Solution 2014. http://okpilot.com/okp_fr/Solution.html 